\title{
Strong Convergence Theorems for a Generalized Mixed Equilibrium Problem and a Family of Total Quasi- $\phi$-Asymptotically Nonexpansive Multivalued Mappings in Banach Spaces
}

\author{
J. F. Tan' ${ }^{1}$ and S. S. Chang ${ }^{2}$ \\ ${ }^{1}$ Department of Mathematics, Yibin University, Yibin 644007, China \\ ${ }^{2}$ College of Statistics and Mathematics, Yunnan University of Finance and Economics, \\ Kunming 650221, China \\ Correspondence should be addressed to S. S. Chang, changss@yahoo.cn \\ Received 30 December 2011; Accepted 2 February 2012 \\ Academic Editor: Khalida Inayat Noor
}

Copyright (C) 2012 J. F. Tan and S. S. Chang. This is an open access article distributed under the Creative Commons Attribution License, which permits unrestricted use, distribution, and reproduction in any medium, provided the original work is properly cited.

The main purpose of this paper is by using a hybrid algorithm to find a common element of the set of solutions for a generalized mixed equilibrium problem, the set of solutions for variational inequality problems, and the set of common fixed points for a infinite family of total quasi- $\phi$ asymptotically nonexpansive multivalued mapping in a real uniformly smooth and strictly convex Banach space with Kadec-Klee property. The results presented in this paper improve and extend some recent results announced by some authors.

\section{Introduction}

Throughout this paper, we always assume that $X$ is a real Banach space with the dual $X^{*}, C$ is a nonempty closed convex subset of $X$, and $J: X \rightarrow 2^{X}$ is the normalized duality mapping defined by

$$
J(x)=\left\{f^{*} \in X^{*}:\left\langle x, f^{*}\right\rangle=\|x\|^{2}=\left\|f^{*}\right\|^{2}\right\}, \quad \forall x \in E .
$$

In the sequel, we use $F(T)$ to denote the set of fixed points of a mapping $T$ and use $\boldsymbol{R}$ and $\boldsymbol{R}^{+}$ to denote the set of all real numbers and the set of all nonnegative real numbers, respectively. We denote by $x_{n} \rightarrow x$ and $x_{n} \rightarrow x$ the strong convergence and weak convergence of a sequence $\left\{x_{n}\right\}$, respectively. 
Let $\Theta: C \times C \rightarrow \mathcal{R}$ be a bifunction, $\psi: C \rightarrow \boldsymbol{R}$ a real valued function, and $A: C \rightarrow X^{*}$ a nonlinear mapping. The so-called generalized mixed equilibrium problem is to find $u \in C$ such that

$$
\Theta(u, y)+\langle A u, y-u\rangle+\psi(y)-\psi(u) \geq 0, \quad \forall y \in C
$$

The set of solutions to (1.2) is denoted by $\Omega$, that is,

$$
\Omega=\{u \in C: \Theta(u, y)+\langle A u, y-u\rangle+\psi(y)-\psi(u) \geq 0, \forall y \in C\}
$$

Special examples are follows.

(i) If $A \equiv 0$, the problem (1.2) is equivalent to finding $u \in C$ such that

$$
\Theta(u, y)+\psi(y)-\psi(u) \geq 0, \quad \forall y \in C,
$$

which is called the mixed equilibrium problem (MEP) [1].

(ii) If $\Theta \equiv 0$, the problem (1.2) is equivalent to finding $u \in C$ such that

$$
\langle A u, y-u\rangle+\psi(y)-\psi(u) \geq 0, \quad \forall y \in C,
$$

which is called the mixed variational inequality of Browder type (VI) [2].

A Banach space $X$ is said to be strictly convex if $\|x+y\| / 2<1$ for all $x, y \in U=\{z \in$ $X:\|z\|=1\}$ with $x \neq y$. $X$ is said to be uniformly convex if, for each $\epsilon \in(0,2]$, there exists $\delta>0$ such that $\|x+y\| / 2<1-\delta$ for all $x, y \in U$ with $\|x-y\| \geq \epsilon$. $X$ is said to be smooth if the limit

$$
\lim _{t \rightarrow 0} \frac{\|x+t y\|-\|x\|}{t}
$$

exists for all $x, y \in U$. $X$ is said to be uniformly smooth if the above limit is attained uniformly in $x, y \in U$.

Remark 1.1. The following basic properties of a Banach space $X$ can be found in Cioranescu [3].

(i) If $X$ is uniformly smooth, then $J$ is uniformly continuous on each bounded subset of $X$.

(ii) If $X$ is a reflexive and strictly convex Banach space, then $J^{-1}$ is norm-weakcontinuous.

(iii) If $X$ is a smooth, strictly convex, and reflexive Banach space, then $J$ is single-valued, one-to-one and onto.

(iv) A Banach space $X$ is uniformly smooth if and only if $X^{*}$ is uniformly convex.

(v) Each uniformly convex Banach space $X$ has the Kadec-Klee property, that is, for any sequence $\left\{x_{n}\right\} \subset X$, if $x_{n} \rightarrow x \in X$ and $\left\|x_{n}\right\| \rightarrow\|x\|$, then $x_{n} \rightarrow x$. 
Let $X$ be a smooth Banach space. We always use $\phi: X \times X \rightarrow R^{+}$to denote the Lyapunov functional defined by

$$
\phi(x, y)=\|x\|^{2}-2\langle x, J y\rangle+\|y\|^{2}, \quad \forall x, y \in X
$$

It is obvious from the definition of the function $\phi$ that

$$
(\|x\|-\|y\|)^{2} \leq \phi(x, y) \leq(\|x\|+\|y\|)^{2}, \quad \forall x, y \in X
$$

Following Alber [4], the generalized projection $\Pi_{C}: X \rightarrow C$ is defined by

$$
\Pi_{C}(x)=\arg \inf _{y \in C} \phi(y, x), \quad \forall x \in X
$$

Lemma 1.2 (see [4]). Let $X$ be a smooth, strictly convex, and reflexive Banach space and $C$ a nonempty closed convex subset of $\mathrm{X}$. Then, the following conclusions hold:

(a) $\phi\left(x, \Pi_{C} y\right)+\phi\left(\Pi_{C} y, y\right) \leq \phi(x, y)$ for all $x \in C$ and $y \in X$,

(b) if $x \in X$ and $z \in C$, then

$$
z=\Pi_{C} x \quad \text { iff }\langle z-y, J x-J z\rangle \geq 0, \quad \forall y \in C,
$$

(c) for $x, y \in X, \phi(x, y)=0$ if and only if $x=y$.

Let $X$ be a smooth, strictly convex, and reflexive Banach space, $C$ a nonempty closed convex subset of $X$, and $T: C \rightarrow C$ a mapping. A point $p \in C$ is said to be an asymptotic fixed point of $T$ if there exists a sequence $\left\{x_{n}\right\} \subset C$ such that $x_{n} \rightarrow p$ and $\left\|x_{n}-T x_{n}\right\| \rightarrow 0$. We denoted the set of all asymptotic fixed points of $T$ by $\widetilde{F}(T)$.

Definition 1.3. (1) A mapping $T: C \rightarrow C$ is said to be relatively nonexpansive [5] if $F(T) \neq \emptyset, F(T)=F(\tilde{T})$ and

$$
\phi(p, T x) \leq \phi(p, x), \quad \forall x \in C, p \in F(T)
$$

(2) A mapping $T: C \rightarrow C$ is said to be closed if, for any sequence $\left\{x_{n}\right\} \subset C$ with $x_{n} \rightarrow x$ and $T x_{n} \rightarrow y, T x=y$.

Let $C$ be a nonempty closed convex subset of a Banach space $X$. Let $N(C)$ be the family of nonempty subsets of $C$. 
Definition 1.4. (1) Let $T: C \rightarrow N(C)$ be a multivalued mapping and $q$ a point in $C$. The definitions of $T q, T^{2} q, T^{3} q, \ldots, T^{n} q, n \geq 1$ are as follows:

$$
\begin{gathered}
T q:=\left\{q_{1}: q_{1} \in T(q)\right\}, \\
T^{2} q=T(T(q)):=\bigcup_{q_{1} \in T(q)} T\left(q_{1}\right), \\
T^{3} q=T\left(T^{2}(q)\right):=\bigcup_{q_{2} \in T^{2}(q)} T\left(q_{2}\right), \\
\vdots \\
T^{n} q=T\left(T^{n-1}(q)\right):=\bigcup_{q_{n-1} \in T^{n-1}(q)} T\left(q^{n-1}\right), \quad n \geq 1 .
\end{gathered}
$$

(2) Let $T: C \rightarrow N(C)$ be a multivalued mapping. A point $p \in C$ is said to be an asymptotic fixed point of $T$ if there exists a sequence $\left\{x_{n}\right\} \subset C$ such that $x_{n} \rightarrow p$ and $\lim _{n \rightarrow \infty} d\left(x_{n}, T\left(x_{n}\right)\right)=0$. We denoted the set of all asymptotic fixed points of $T$ by $\widetilde{F}(T)$.

(3) A multivalued mapping $T: C \rightarrow N(C)$ is said to be relatively nonexpansive [5] if $F(T) \neq \emptyset, F(T)=\widetilde{F}(T)$ and

$$
\phi(p, w) \leq \phi(p, x), \quad \forall x \in C, w \in T x, p \in F(T) .
$$

(4) A multivalued mapping $T: C \rightarrow N(C)$ is said to be closed if, for any sequence $\left\{x_{n}\right\} \subset C$ with $x_{n} \rightarrow x$ and $w_{n} \in T\left(x_{n}\right)$ with $w_{n} \rightarrow y$, then $y \in T x$.

Definition 1.5. (1) A multivalued mapping $T: C \rightarrow N(C)$ is said to be quasi- $\phi$-nonexpansive if $F(T) \neq \emptyset$ and

$$
\phi(p, w) \leq \phi(p, x), \quad \forall x \in C, w \in T x, p \in F(T) .
$$

(2) A multivalued mapping $T: C \rightarrow N(C)$ is said to be quasi- $\phi$-asymptotically nonexpansive if $F(T) \neq \emptyset$ and there exists a real sequence $\left\{k_{n}\right\} \subset[1, \infty)$ with $k_{n} \rightarrow 1$ such that

$$
\phi\left(p, w_{n}\right) \leq k_{n} \phi(p, x), \quad \forall n \geq 1, x \in C, w_{n} \in T^{n} x, p \in F(T) .
$$

(3) A multivalued mapping $T: C \rightarrow N(C)$ is said to be total quasi- $\phi$-asymptotically nonexpansive if $F(T) \neq \emptyset$ and there exist nonnegative real sequences $\left\{v_{n}\right\},\left\{\mu_{n}\right\}$ with $v_{n} \rightarrow$ $0, \mu_{n} \rightarrow 0($ as $n \rightarrow \infty)$ and a strictly increasing continuous function $\zeta: R^{+} \rightarrow R^{+}$with $\zeta(0)=0$ such that for all $x \in C, p \in F(T)$

$$
\phi\left(p, w_{n}\right) \leq \phi(p, x)+v_{n} \zeta(\phi(p, x))+\mu_{n}, \quad \forall n \geq 1, w_{n} \in T^{n} x
$$


Definition 1.6. (1) Let $\left\{T_{i}\right\}_{i=1}^{\infty}: C \rightarrow N(C)$ be a sequence of mappings. $\left\{T_{i}\right\}_{i=1}^{\infty}$ is said to be $a$ family of uniformly total quasi- $\phi$-asymptotically nonexpansive multivalued mappings if $\cap_{i=1}^{\infty} F\left(T_{i}\right) \neq \emptyset$ and there exist nonnegative real sequences $\left\{v_{n}\right\},\left\{\mu_{n}\right\}$ with $v_{n} \rightarrow 0, \mu_{n} \rightarrow 0($ as $n \rightarrow \infty)$ and a strictly increasing continuous function $\zeta: \mathcal{R}^{+} \rightarrow \mathcal{R}^{+}$with $\zeta(0)=0$ such that for all $i \geq 1, x \in C, p \in \cap_{i=1}^{\infty} F\left(T_{i}\right)$

$$
\phi\left(p, w_{n, i}\right) \leq \phi(p, x)+v_{n} \zeta(\phi(p, x))+\mu_{n}, \quad \forall w_{n, i} \in T_{i}^{n} x, \forall n \geq 1
$$

(2) A total quasi- $\phi$-asymptotically nonexpansive multivalued mapping $T: C \rightarrow N(C)$ is said to be uniformly L-Lipschitz continuous if there exists a constant $L>0$ such that

$$
\left\|w_{n}-s_{n}\right\| \leq L\|x-y\|, \quad \forall x, y \in C, w_{n} \in T^{n} x, s_{n} \in T^{n} y, n \geq 1
$$

In 2005, Matsushita and Takahashi [5] proved weak and strong convergence theorems to approximate a fixed point of a single relatively nonexpansive mapping in a uniformly convex and uniformly smooth Banach space X. In 2008, Plubtieng and Ungchittrakool [6] proved the strong convergence theorems to approximate a fixed point of two relatively nonexpansive mappings in a uniformly convex and uniformly smooth Banach space $X$. In 2010, Chang et al. [7] obtained the strong convergence theorem for an infinite family of quasi- $\phi$-asymptotically nonexpansive mappings in a uniformly smooth and strictly convex Banach space $X$ with Kadec-Klee property. In 2011, Chang et al. [8] proved some approximation theorems of common fixed points for countable families of total quasi- $\phi$ asymptotically nonexpansive mappings in a uniformly smooth and strictly convex Banach space $X$ with Kadec-Klee property. In 2011, Homaeipour and Razani [9] proved weak and strong convergence theorems for a single relatively nonexpansive multivalued mapping in a uniformly convex and uniformly smooth Banach space $X$. On the other hand, In 2009, Zhang [10] proved the strong convergence theorem for finding a common element of the set of solutions of a generalized mixed equilibrium problem, the set of solutions for variational inequality problems, and the set of fixed points of a finite family of quasi$\phi$-asymptotically nonexpansive mappings in a uniformly smooth and uniformly convex Banach space. Recently, Tang [11], Cho et al. [12-21], and Noor et al. [22-26] extended the finite family of quasi- $\phi$-asymptotically nonexpansive mappings to infinite family of quasi- $\phi$ asymptotically nonexpansive mappings.

Motivated and inspired by the researches going on in this direction, the purpose of this paper is by using the hybrid iterative algorithm to find a common element of the set of solutions of a generalized mixed equilibrium problem, the set of solutions for variational inequality problems, and the set of fixed points of a infinite family of total quasi$\phi$-asymptotically nonexpansive multivalued mappings in a uniformly smooth and strictly convex Banach space with Kadec-Klee property. In order to get the strong convergence theorems, the hybrid algorithms are presented and used to approximate the fixed point. The results presented in the paper improve and extend some recent results announced by some authors. 


\section{Preliminaries}

Lemma 2.1 (see [8]). Let X be a real uniformly smooth and strictly convex Banach space with KadecKlee property and $C$ a nonempty closed convex set of $X$. Let $\left\{x_{n}\right\}$ and $\left\{y_{n}\right\}$ be two sequences in $C$ such that $x_{n} \rightarrow p$ and $\phi\left(x_{n}, y_{n}\right) \rightarrow 0$, where $\phi$ is the function defined by (1.7), and then $y_{n} \rightarrow p$.

Lemma 2.2. Let $X$ and $C$ be as in Lemma 2.1. Let $T: C \rightarrow N(C)$ be a closed and total quasi- $\phi$ asymptotically nonexpansive multivalued mapping with nonnegative real sequences $\left\{v_{n}\right\},\left\{\mu_{n}\right\}$ and a strictly increasing continuous function $\zeta: \mathcal{R}^{+} \rightarrow \mathcal{R}^{+}$such that $v_{n} \rightarrow 0, \mu_{n} \rightarrow 0$ (as $n \rightarrow \infty$ ), and $\zeta(0)=0$. If $\mu_{1}=0$, then the fixed point set $F(T)$ is a closed and convex subset of $C$.

Proof. Letting $\left\{x_{n}\right\}$ be a sequence in $F(T)$ with $x_{n} \rightarrow p$ (as $\left.n \rightarrow \infty\right)$, we prove that $p \in F(T)$. In fact, by the assumption that $T$ is a total quasi- $\phi$-asymptotically nonexpansive multivalued mapping and $\mu_{1}=0$, we have

$$
\phi\left(x_{n}, u\right) \leq \phi\left(x_{n}, p\right)+v_{1} \zeta\left(\phi\left(x_{n}, p\right)\right), \quad \forall u \in T p .
$$

Furthermore, we have

$$
\begin{aligned}
\phi(p, u) & =\lim _{n \rightarrow \infty} \phi\left(x_{n}, u\right) \\
& \leq \lim _{n \rightarrow \infty}\left(\phi\left(x_{n}, p\right)+v_{1} \zeta\left(\phi\left(x_{n}, p\right)\right)\right)=0, \quad \forall u \in T p .
\end{aligned}
$$

By Lemma 1.2(c), $p=u$. Hence, $p \in T p$. This implies that $p \in F(T)$, that is, $F(T)$ is closed.

Next, we prove that $F(T)$ is convex. For any $x, y \in F(T), t \in(0,1)$, putting $q=t x+$ $(1-t) y$, we prove that $q \in F(T)$. Indeed, let $\left\{u_{n}\right\}$ be a sequence generated by

$$
\begin{gathered}
u_{1} \in T q, \\
u_{2} \in T u_{1} \subset T^{2} q, \\
u_{3} \in T u_{2} \subset T^{3} q, \\
\vdots \\
u_{n} \in T u_{n-1} \subset T^{n} q,
\end{gathered}
$$

In view of the definition of $\phi(x, y)$, for all $u_{n} \in T u_{n-1} \subset T^{n} q$, we have

$$
\begin{aligned}
\phi\left(q, u_{n}\right) & =\|q\|^{2}-2\left\langle q, J u_{n}\right\rangle+\left\|u_{n}\right\|^{2} \\
& =\|q\|^{2}-2 t\left\langle x, J u_{n}\right\rangle-2(1-t)\left\langle y, J u_{n}\right\rangle+\left\|u_{n}\right\|^{2} \\
& =\|q\|^{2}+t \phi\left(x, u_{n}\right)+(1-t) \phi\left(y, u_{n}\right)-t\|x\|^{2}-(1-t)\|y\|^{2}
\end{aligned}
$$


since

$$
\begin{aligned}
& t \phi\left(x, u_{n}\right)+(1-t) \phi\left(y, u_{n}\right) \\
& \leq t\left(\phi(x, q)+v_{n} \zeta(\phi(x, q))+\mu_{n}\right)+(1-t)\left(\phi(y, q)+v_{n} \zeta(\phi(y, q))+\mu_{n}\right) \\
&= t\left(\|x\|^{2}-2\langle x, J q\rangle+\|q\|^{2}+v_{n} \zeta(\phi(x, q))+\mu_{n}\right) \\
&+(1-t)\left(\|y\|^{2}-2\langle y, J q\rangle+\|q\|^{2}+v_{n} \zeta(\phi(y, q))+\mu_{n}\right) \\
&= t\|x\|^{2}+(1-t)\|y\|^{2}-\|q\|^{2}+t v_{n} \zeta(\phi(x, q))+(1-t) v_{n} \zeta(\phi(y, q))+\mu_{n} .
\end{aligned}
$$

Substituting (2.5) into (2.4) and simplifying it, we have

$$
\phi\left(q, u_{n}\right) \leq t v_{n} \zeta(\phi(x, q))+(1-t) v_{n} \zeta(\phi(y, q))+\mu_{n} \longrightarrow 0 \quad(n \longrightarrow \infty) .
$$

By Lemma 2.1, we have $u_{n} \rightarrow q($ as $n \rightarrow \infty)$. This implies that $u_{n+1} \rightarrow q($ as $n \rightarrow \infty)$. Since $T$ is closed, we have $q \in T q$, that is, $q \in F(T)$.

This completes the proof of Lemma 2.2.

Lemma 2.3 (see [7]). Let $X$ be a uniformly convex Banach space, $r>0$, a positive number, and $B_{r}(0)$ a closed ball of $X$. Then, for any given sequence $\left\{x_{n}\right\}_{n=1}^{\infty} \subset B_{r}(0)$ and for any given sequence $\left\{\lambda_{n}\right\}_{n=1}^{\infty}$ of positive numbers with $\sum_{n=1}^{\infty} \lambda_{n}=1$, there exists a continuous, strictly increasing, and convex function $g:[0,2 r) \rightarrow[0, \infty)$ with $g(0)=0$ such that for any positive integers $i, j$ with $i<j$,

$$
\left\|\sum_{n=1}^{\infty} \lambda_{n} x_{n}\right\|^{2} \leq \sum_{n=1}^{\infty} \lambda_{n}\left\|x_{n}\right\|^{2}-\lambda_{i} \lambda_{j} g\left(\left\|x_{i}-x_{j}\right\|\right) .
$$

For solving the generalized mixed equilibrium problem, let us assume that the function $\psi$ : $C \rightarrow \mathcal{R}$ is convex and lower semicontinuous, the nonlinear mapping $A: C \rightarrow X^{*}$ is continuous and monotone, and the bifunction $\Theta: C \times C \rightarrow R$ satisfies the following conditions:

$\left(\mathrm{A}_{1}\right) \Theta(x, x)=0$, for all $x \in C$,

$\left(\mathrm{A}_{2}\right) \Theta$ is monotone, that is, $\Theta(x, y)+\Theta(y, x) \leq 0$, for all $x, y \in C$,

$\left(\mathrm{A}_{3}\right) \lim \sup _{t \downarrow 0} \Theta(x+t(z-x), y) \leq \Theta(x, y)$, for all $x, y, z \in C$,

$\left(\mathrm{A}_{4}\right)$ the function $y \mapsto \Theta(x, y)$ is convex and lower semicontinuous.

Lemma 2.4. Let $X$ be a smooth, strictly convex and reflexive Banach space and $C$ a nonempty closed convex subset of $X$. Let $\Theta: C \times C \rightarrow R$ be a bifunction satisfying conditions $\left(A_{1}\right)-\left(A_{4}\right)$. Let $r>0$ and $x \in X$. Then, the following hold.

(i) [27] There exists $z \in C$ such that

$$
\Theta(z, y)+\frac{1}{r}\langle y-z, J z-J x\rangle \geq 0, \quad \forall y \in C
$$


(ii) [28] Define a mapping $T_{r}: X \rightarrow C$ by

$$
T_{r} x=\left\{z \in C: \Theta(z, y)+\frac{1}{r}\langle y-z, J z-J x\rangle \geq 0, \forall y \in C\right\}, \quad x \in X .
$$

Then, the following conclusions hold:

(a) $T_{r}$ is single-valued,

(b) $T_{r}$ is a firmly nonexpansive-type mapping, that is, for all $z, y \in X$,

$$
\left\langle T_{r}(z)-T_{r}(y), J T_{r}(z)-J T_{r}(y)\right\rangle \leq\left\langle T_{r}(z)-T_{r}(y), J z-J y\right\rangle,
$$

(c) $F\left(T_{r}\right)=E P(\Theta)=\widehat{F\left(T_{r}\right)}$,

(d) $E P(\Theta)$ is closed and convex,

(e) $\phi\left(q, T_{r}(x)\right)+\phi\left(T_{r}(x), x\right) \leq \phi(q, x)$, for all $q \in F\left(T_{r}\right)$.

Lemma 2.5 (see [10]). Let $X$ be a smooth, strictly convex, and reflexive Banach space and $C$ a nonempty closed convex subset of $\mathrm{X}$. Let $A: C \rightarrow X^{*}$ be a continuous and monotone mapping, $\psi: C \rightarrow \mathcal{R}$ a lower semicontinuous and convex function, and $\Theta: C \times C \rightarrow \mathcal{R}$ a bifunction satisfying conditions $\left(A_{1}\right)-\left(A_{4}\right)$. Let $r>0$ be any given number and $x \in X$ any given point. Then, the following hold.

(i) There exists $u \in C$ such that for all $y \in C$

$$
\Theta(u, y)+\langle A u, y-u\rangle+\psi(y)-\psi(u)+\frac{1}{r}\langle y-u, J u-J x\rangle \geq 0 .
$$

(ii) If one defines a mapping $K_{r}: C \rightarrow C$ by

$$
\begin{aligned}
& K_{r}(x)=\{u \in C: \Theta(u, y)+\langle A u, y-u\rangle+\psi(y)-\psi(u) \\
&\left.+\frac{1}{r}\langle y-u, J u-J x\rangle \geq 0, \forall y \in C\right\}, \quad x \in C,
\end{aligned}
$$

then, the mapping $K_{r}$ has the following properties:

(a) $K_{r}$ is single-valued,

(b) $K_{r}$ is a firmly nonexpansive-type mapping, that is, for all $z, y \in X$

$$
\left\langle K_{r}(z)-K_{r}(y), J K_{r}(z)-J K_{r}(y)\right\rangle \leq\left\langle K_{r}(z)-K_{r}(y), J z-J y\right\rangle,
$$

(c) $F\left(K_{r}\right)=\Omega=\widehat{F\left(K_{r}\right)}$,

(d) $\Omega$ is a closed convex set of $C$,

(e) $\phi\left(p, K_{r}(z)\right)+\phi\left(K_{r}(z), z\right) \leq \phi(p, z)$, for all $p \in F\left(K_{r}\right), z \in X$. 
Remark 2.6. It follows from Lemma 2.4 that the mapping $K_{r}: C \rightarrow C$ defined by (2.12) is a relatively nonexpansive mapping. Thus, it is quasi- $\phi$-nonexpansive.

\section{Main Results}

In this section, we will use the hybrid iterative algorithm to find a common element of the set of solutions of a generalized mixed equilibrium problem, the set of solutions for variational inequality problems, and the set of fixed points of a infinite family of total quasi$\phi$-asymptotically nonexpansive multivalued mappings in a uniformly smooth and strictly convex Banach space with Kadec-Klee property.

Theorem 3.1. Let $X$ be a real uniformly smooth and strictly convex Banach space with Kadec-Klee property and $C$ a nonempty closed and convex subset of $X$. Let $\Theta: C \times C \rightarrow R$ be a bifunction satisfying conditions $\left(A_{1}\right)-\left(A_{4}\right), A: C \rightarrow X^{*}$ a continuous and monotone mapping, and $\psi: C \rightarrow \mathcal{R}$ a lower semicontinuous and convex function. Let $\left\{T_{i}\right\}_{i=1}^{\infty}: C \rightarrow N(C)$ be an infinite family of closed and uniformly total quasi- $\phi$-asymptotically nonexpansive multivalued mappings with nonnegative real sequences $\left\{v_{n}\right\},\left\{\mu_{n}\right\}$ and a strictly increasing continuous function $\zeta: R^{+} \rightarrow R^{+}$such that $\mu_{1}=0, v_{n} \rightarrow 0, \mu_{n} \rightarrow 0$ (as $n \rightarrow \infty$ ) and $\zeta(0)=0$ and for each $i \geq 1, T_{i}$ is uniformly $L_{i}$-Lipschitz continuous. Let $x_{0} \in C, C_{0}=C$, and let $\left\{x_{n}\right\}$ be a sequence generated by

$$
\begin{gathered}
x_{n+1}=\prod_{C_{n+1}} x_{0}, \quad C_{n+1}=\left\{v \in C_{n}: \phi\left(v, u_{n}\right) \leq \phi\left(v, x_{n}\right)+\xi_{n}\right\}, \quad \forall n \geq 0, \\
y_{n}=J^{-1}\left(\alpha_{n} J x_{n}+\left(1-\alpha_{n}\right) J z_{n}\right), \\
z_{n}=J^{-1}\left(\beta_{n, 0} J x_{n}+\sum_{i=1}^{\infty} \beta_{n, i} J w_{n, i}\right), \\
u_{n} \in C \text { such that }, \forall y \in C, \\
\Theta\left(u_{n}, y\right)+\left\langle A u_{n}, y-u_{n}\right\rangle+\psi(y)-\psi\left(u_{n}\right)+\frac{1}{r_{n}}\left\langle y-u_{n}, J u_{n}-J y_{n}\right\rangle \geq 0,
\end{gathered}
$$

where $w_{n, i} \in T_{i}^{n} x_{n}$, for all $n \geq 1, i \geq 1, \xi_{n}=v_{n} \sup _{p \in \mathcal{F}} \zeta\left(\phi\left(p, x_{n}\right)\right)+\mu_{n}, \Pi_{C_{n+1}}$ is the generalized projection of $X$ onto $C_{n+1}$, and $\left\{\alpha_{n}\right\}$ and $\left\{\beta_{n, 0}, \beta_{n, i}\right\}$ are sequences in $[0,1]$ satisfying the following conditions:

(a) for each $n \geq 0, \beta_{n, 0}+\sum_{i=1}^{\infty} \beta_{n, i}=1$,

(b) $\liminf _{n \rightarrow \infty} \beta_{n, 0} \beta_{n i}>0$ for any $i \geq 1$,

(c) $0 \leq \alpha_{n} \leq \alpha<1$ for some $\alpha \in(0,1)$.

If $G:=\mathscr{F} \cap \Omega=\cap_{i=1}^{\infty} F\left(T_{i}\right) \cap \Omega$ is a nonempty and bounded subset of $C$, then the sequence $\left\{x_{n}\right\}$ converges strongly to $\Pi_{G} x_{0}$.

Proof. First, we define two functions $H: C \times C \rightarrow R$ and $K_{r}: C \rightarrow C$ by

$$
\begin{gathered}
H(x, y)=\Theta(x, y)+\langle A x, y-x\rangle+\psi(y)-\psi(x), \quad \forall x, y \in C, \\
K_{r}(x)=\left\{u \in C: H(u, y)+\frac{1}{r}\langle y-u, J u-J x\rangle \geq 0, \forall y \in C\right\}, \quad x \in C .
\end{gathered}
$$


By Lemma 2.5, we know that the function $H$ satisfies conditions $\left(\mathrm{A}_{1}\right)-\left(\mathrm{A}_{4}\right)$ and $K_{r}$ has properties (a)-(e). Therefore, (3.1) is equivalent to

$$
\begin{gathered}
x_{n+1}=\prod_{C_{n+1}} x_{0}, \quad C_{n+1}=\left\{v \in C_{n}: \phi\left(v, u_{n}\right) \leq \phi\left(v, x_{n}\right)+\xi_{n}\right\}, \quad \forall n \geq 0, \\
y_{n}=J^{-1}\left(\alpha_{n} J x_{n}+\left(1-\alpha_{n}\right) J z_{n}\right), \\
z_{n}=J^{-1}\left(\beta_{n, 0} J x_{n}+\sum_{i=1}^{\infty} \beta_{n, i} J w_{n, i}\right), \\
u_{n} \in C \text { such that, } \forall y \in C, \\
H\left(u_{n}, y\right)+\frac{1}{r_{n}}\left\langle y-u_{n}, J u_{n}-J y_{n}\right\rangle \geq 0 .
\end{gathered}
$$

Now we divide the proof of Theorem 3.1 into six steps.

(i) $F$ and $C_{n}$ are closed and convex for each $n \geq 0$.

In fact, it follows from Lemma 2.2 that $F\left(T_{i}\right), i \geq 1$, is a closed and convex subset of $C$. Therefore, $\mathcal{F}$ is a closed and convex subset $C$.

Again by the assumption, $C_{0}=C$ is closed and convex. Suppose that $C_{n}$ is closed and convex for some $n \geq 1$. Since the condition $\phi\left(v, y_{n}\right) \leq \phi\left(v, x_{n}\right)+\xi_{n}$ is equivalent to

$$
2\left\langle v, J x_{n}-J y_{n}\right\rangle \leq\left\|x_{n}\right\|^{2}-\left\|y_{n}\right\|^{2}+\xi_{n}, \quad n=1,2, \ldots,
$$

the set

$$
C_{n+1}=\left\{v \in C_{n}: 2\left\langle v, J x_{n}-J y_{n}\right\rangle \leq\left\|x_{n}\right\|^{2}-\left\|y_{n}\right\|^{2}+\xi_{n}\right\}
$$

is closed and convex. Therefore, $C_{n}$ is closed and convex for each $n \geq 0$.

(ii) $\left\{x_{n}\right\}$ is bounded and $\left\{\phi\left(x_{n}, x_{0}\right)\right\}$ is a convergent sequence.

Indeed, it follows from (3.1) and Lemma 1.2(a) that for all $n \geq 0, u \in F(T)$

$$
\phi\left(x_{n}, x_{0}\right)=\phi\left(\prod_{C_{n}} x_{0}, x_{0}\right) \leq \phi\left(u, x_{0}\right)-\phi\left(u, \prod_{C_{n}} x_{0}\right) \leq \phi\left(u, x_{0}\right) .
$$

This implies that $\left\{\phi\left(x_{n}, x_{0}\right)\right\}$ is bounded. By virtue of (1.3), we know that $\left\{x_{n}\right\}$ is bounded.

In view of the structure of $\left\{C_{n}\right\}$, we have $C_{n+1} \subset C_{n}, x_{n}=\Pi_{C_{n}} x_{0}$ and $x_{n+1}=\Pi_{C_{n+1}} x_{0}$. This implies that $x_{n+1} \in C_{n}$ and

$$
\phi\left(x_{n}, x_{0}\right) \leq \phi\left(x_{n+1}, x_{0}\right), \quad \forall n \geq 0 .
$$

Therefore, $\left\{\phi\left(x_{n}, x_{0}\right)\right\}$ is a convergent sequence.

(iii) $G:=\mathscr{F} \cap \Omega \subset C_{n}$ for all $n \geq 0$. 
Indeed, it is obvious that $G \subset C_{0}=C$. Suppose that $G \subset C_{n}$ for some $n \in \mathcal{N}$. Since $u_{n}=K_{r_{n}} y_{n}$, by Lemma 2.5 and Remark $2.6, K_{r_{n}}$ is quasi- $\phi$-nonexpansive. Hence, for any given $u \in G \subset C_{n}$ and $n \geq 1$ we have

$$
\begin{aligned}
\phi\left(u, u_{n}\right)= & \phi\left(u, K_{r_{n}} y_{n}\right) \leq \phi\left(u, y_{n}\right) \\
= & \phi\left(u, J^{-1}\left(\alpha_{n} J x_{n}+\left(1-\alpha_{n}\right) J z_{n}\right)\right) \\
= & \|u\|^{2}-2\left\langle u, \alpha_{n} J x_{n}+\left(1-\alpha_{n}\right) J z_{n}\right\rangle+\left\|\alpha_{n} J x_{n}+\left(1-\alpha_{n}\right) J z_{n}\right\|^{2} \\
\leq & \|u\|^{2}-2 \alpha_{n}\left\langle u, J x_{n}\right\rangle-2\left(1-\alpha_{n}\right)\left\langle u, J z_{n}\right\rangle+\alpha_{n}\left\|x_{n}\right\|^{2} \\
& +\left(1-\alpha_{n}\right)\left\|z_{n}\right\|^{2} \\
= & \alpha_{n} \phi\left(u, x_{n}\right)+\left(1-\alpha_{n}\right) \phi\left(u, z_{n}\right) .
\end{aligned}
$$

Furthermore, it follows from Lemma 2.3 that for any $u \in G \subset C_{n}, w_{n, i} \in T_{i}^{n} x_{n}$, and $i \geq 1$ we have

$$
\begin{aligned}
\phi\left(u, z_{n}\right)= & \phi\left(u, J^{-1}\left(\beta_{n, 0} J x_{n}+\sum_{i=1}^{\infty} \beta_{n, i} J w_{n, i}\right)\right) \\
= & \|u\|^{2}-2\left\langle u, \beta_{n, 0} J x_{n}+\sum_{i=1}^{\infty} \beta_{n, i} J w_{n, i}\right\rangle+\left\|\beta_{n, 0} J x_{n}+\sum_{i=1}^{\infty} \beta_{n, i} J w_{n, i}\right\|^{2} \\
\leq & \|u\|^{2}-2 \beta_{n, 0}\left\langle u, J x_{n}\right\rangle-2 \sum_{i=1}^{\infty} \beta_{n, i}\left\langle u, J w_{n, i}\right\rangle+\beta_{n, 0}\left\|x_{n}\right\|^{2} \\
& +\sum_{i=1}^{\infty} \beta_{n, i}\left\|w_{n, i}\right\|^{2}-\beta_{n, 0} \beta_{n, l} g\left(\left\|J x_{n}-J w_{n, l}\right\|\right) \\
= & \beta_{n, 0} \phi\left(u, x_{n}\right)+\sum_{i=1}^{\infty} \beta_{n, i} \phi\left(u, w_{n, i}\right)-\beta_{n, 0} \beta_{n, l} g\left(\left\|J x_{n}-J w_{n, l}\right\|\right) \\
\leq & \beta_{n, 0} \phi\left(u, x_{n}\right)+\sum_{i=1}^{\infty} \beta_{n, i}\left(\phi\left(u, x_{n}\right)+v_{n} \zeta\left(\phi\left(u, x_{n}\right)\right)+\mu_{n}\right) \\
& -\beta_{n, 0} \beta_{n, l} g\left(\left\|J x_{n}-J w_{n, l}\right\|\right) \\
\leq & \phi\left(u, x_{n}\right)+v_{n} \sup _{p \in \mathscr{T}} \zeta\left(\phi\left(p, x_{n}\right)\right)+\mu_{n}-\beta_{n, 0} \beta_{n, l} g\left(\left\|J x_{n}-J w_{n, l}\right\|\right) \\
= & \phi\left(u, x_{n}\right)+\xi_{n}-\beta_{n, 0} \beta_{n, l} g\left(\left\|J x_{n}-J w_{n, l}\right\|\right) .
\end{aligned}
$$

Substituting (3.9) into (3.8) and simplifying it, we have for all $u \in G$

$$
\begin{aligned}
\phi\left(u, u_{n}\right) & \leq \phi\left(u, y_{n}\right) \\
& \leq \phi\left(u, x_{n}\right)+\left(1-\alpha_{n}\right) \xi_{n}-\left(1-\alpha_{n}\right) \beta_{n, 0} \beta_{n, l} g\left(\left\|J x_{n}-J w_{n, l}\right\|\right)
\end{aligned}
$$




$$
\begin{aligned}
& \leq \phi\left(u, x_{n}\right)+\xi_{n}-\left(1-\alpha_{n}\right) \beta_{n, 0} \beta_{n, l} g\left(\left\|J x_{n}-J w_{n, l}\right\|\right) \\
& \leq \phi\left(u, x_{n}\right)+\xi_{n}
\end{aligned}
$$

that is, $u \in C_{n+1}$ and so $G \subset C_{n+1}$ for all $n \geq 0$.

By the way, in view of the assumption on $\left\{v_{n}\right\},\left\{\mu_{n}\right\}$ we have

$$
\xi_{n}=v_{n} \sup _{p \in \mathscr{F}} \zeta\left(\phi\left(p, x_{n}\right)\right)+\mu_{n} \longrightarrow 0 \quad(n \longrightarrow \infty)
$$

(iv) $\left\{x_{n}\right\}$ converges strongly to some point $p^{*} \in C$.

In fact, since $\left\{x_{n}\right\}$ is bounded and $X$ is reflexive, there exists a subsequence $\left\{x_{n_{i}}\right\} \subset$ $\left\{x_{n}\right\}$ such that $x_{n_{i}} \rightarrow p^{*}$ (some point in $C$ ). Since $C_{n}$ is closed and convex and $C_{n+1} \subset C_{n}$, this implies that $C_{n}$ is weakly closed and $p^{*} \in C_{n}$ for each $n \geq 0$. In view of $x_{n_{i}}=\Pi_{C_{n_{i}}} x_{0}$, we have

$$
\phi\left(x_{n_{i}}, x_{0}\right) \leq \phi\left(p^{*}, x_{0}\right), \quad \forall n_{i} \geq 0 .
$$

Since the norm $\|\cdot\|$ is weakly lower semicontinuous, we have

$$
\begin{aligned}
\liminf _{n_{i} \rightarrow \infty} \phi\left(x_{n_{i}}, x_{0}\right) & =\liminf _{n_{i} \rightarrow \infty}\left(\left\|x_{n_{i}}\right\|^{2}-2\left\langle x_{n_{i}}, J x_{0}\right\rangle+\left\|x_{0}\right\|^{2}\right) \\
& \geq\left\|p^{*}\right\|^{2}-2\left\langle p^{*}, J x_{0}\right\rangle+\left\|x_{0}\right\|^{2}=\phi\left(p^{*}, x_{0}\right),
\end{aligned}
$$

and so

$$
\phi\left(p^{*}, x_{0}\right) \leq \liminf _{n_{i} \rightarrow \infty} \phi\left(x_{n_{i}}, x_{0}\right) \leq \limsup _{n_{i} \rightarrow \infty} \phi\left(x_{n_{i}}, x_{0}\right) \leq \phi\left(p^{*}, x_{0}\right)
$$

This implies that $\lim _{n_{i} \rightarrow \infty} \phi\left(x_{n_{i}}, x_{0}\right)=\phi\left(p^{*}, x_{0}\right)$, and so $\left\|x_{n_{i}}\right\| \rightarrow\left\|p^{*}\right\|$. Since $x_{n_{i}} \rightarrow p^{*}$, by virtue of Kadec-Klee property of $X$, we obtain that

$$
\lim _{n_{i} \rightarrow \infty} x_{n_{i}}=p^{*}
$$

Since $\left\{\phi\left(x_{n}, x_{0}\right)\right\}$ is convergent, this together with $\lim _{n_{i} \rightarrow \infty} \phi\left(x_{n_{i}}, x_{0}\right)=\phi\left(p^{*}, x_{0}\right)$, shows that $\lim _{n \rightarrow \infty} \phi\left(x_{n}, x_{0}\right)=\phi\left(p^{*}, x_{0}\right)$. If there exists some sequence $\left\{x_{n_{j}}\right\} \subset\left\{x_{n}\right\}$ such that $x_{n_{j}} \rightarrow q$, then from Lemma 1.2(a) we have that

$$
\begin{aligned}
\phi\left(p^{*}, q\right) & =\lim _{n_{i}, n_{j} \rightarrow \infty} \phi\left(x_{n_{i}}, x_{n_{j}}\right)=\lim _{n_{i}, n_{j} \rightarrow \infty} \phi\left(x_{n_{i}}, \prod_{C_{n_{j}}} x_{0}\right) \\
& \leq \lim _{n_{i}, n_{j} \rightarrow \infty}\left(\phi\left(x_{n_{i}}, x_{0}\right)-\phi\left(\prod_{C_{n_{j}}} x_{0}, x_{0}\right)\right)
\end{aligned}
$$


Abstract and Applied Analysis

$$
\begin{aligned}
& =\lim _{n_{i}, n_{j} \rightarrow \infty}\left(\phi\left(x_{n_{i}}, x_{0}\right)-\phi\left(x_{n_{j}}, x_{0}\right)\right) \\
& =\phi\left(p^{*}, x_{0}\right)-\phi\left(p^{*}, x_{0}\right)=0 .
\end{aligned}
$$

This implies that $p^{*}=q$ and

$$
\lim _{n \rightarrow \infty} x_{n}=p^{*}
$$

(v) Now we prove that $p^{*} \in G=\mathcal{F} \cap \Omega$.

First, we prove that $p^{*} \in \mathcal{F}$. In fact, since $x_{n+1} \in C_{n+1} \subset C_{n}$, it follows from (3.1) and (3.17) that

$$
\phi\left(x_{n+1}, y_{n}\right) \leq \phi\left(x_{n+1}, x_{n}\right)+\xi_{n} \longrightarrow 0 \quad(n \longrightarrow \infty)
$$

By the virtue of Lemma 2.1, we have

$$
\lim _{n \rightarrow \infty} y_{n}=p^{*}
$$

From (3.10), for any $u \in \mathcal{F}$ and $w_{n, i} \in T_{i}^{n} x_{n}$, we have

$$
\phi\left(u, y_{n}\right) \leq \phi\left(u, x_{n}\right)+\xi_{n}-\left(1-\alpha_{n}\right) \beta_{n, 0} \beta_{n, l} g\left(\left\|J x_{n}-J w_{n, l}\right\|\right),
$$

that is,

$$
\left(1-\alpha_{n}\right) \beta_{n, 0} \beta_{n, l} g\left(\left\|J x_{n}-J w_{n, l}\right\|\right) \leq \phi\left(u, x_{n}\right)+\xi_{n}-\phi\left(u, y_{n}\right) \longrightarrow 0 \quad(n \longrightarrow \infty)
$$

By conditions (b) and (c) it is shown that $\lim _{n \rightarrow \infty} g\left(\left\|J x_{n}-J w_{n, l}\right\|\right)=0$. In view of property of $g$, we have

$$
\left\|J x_{n}-J w_{n, l}\right\| \longrightarrow 0 \quad(n \longrightarrow \infty)
$$

Since $J x_{n} \rightarrow J p^{*}$, this implies that $J w_{n, l} \rightarrow J p^{*}$. From Remark 1.1(ii) it yields

$$
w_{n, l} \rightarrow p^{*}(n \longrightarrow \infty), \quad \forall l \geq 1
$$

Again since

$$
\left|\left\|w_{n, l}\right\|-\left\|p^{*}\right\|\right|=\left|\left\|J w_{n, l}\right\|-\left\|J p^{*}\right\|\right| \leq\left\|J w_{n, l}-J p^{*}\right\| \longrightarrow 0 \quad(n \longrightarrow \infty),
$$

this together with (3.23) and the Kadec-Klee property of X shows that

$$
\lim _{n \rightarrow \infty} w_{n, l}=p^{*}, \quad \forall l \geq 1
$$


Let $\left\{s_{n, l}\right\}$ be a sequence generated by

$$
\begin{gathered}
s_{2, l} \in T_{l} w_{1, l} \subset T_{l}^{2} x_{1}, \\
s_{3, l} \in T_{l} w_{2, l} \subset T_{l}^{3} x_{2}, \\
\vdots \\
s_{n+1, l} \in T_{l} w_{n, l} \subset T_{l}^{n+1} x_{n},
\end{gathered}
$$

By the assumption that each $T_{i}$ is uniformly $L_{i}$-Lipschitz continuous, for any $w_{n, l} \in T_{l}^{n} x_{n}$ and $s_{n+1, l} \in T_{l} w_{n} \subset T_{l}^{n+1} x_{n}$ we have

$$
\begin{aligned}
\left\|s_{n+1, l}-w_{n, l}\right\| & \leq\left\|s_{n+1, l}-w_{n+1,1}\right\|+\left\|w_{n+1, l}-x_{n+1}\right\|+\left\|x_{n+1}-x_{n}\right\|+\left\|x_{n}-w_{n, l}\right\| \\
& \leq\left(L_{l}+1\right)\left\|x_{n+1}-x_{n}\right\|+\left\|w_{n+1, l}-x_{n+1}\right\|+\left\|x_{n}-w_{n, l}\right\| .
\end{aligned}
$$

This together with (3.17) and (3.27) shows that $\lim _{n \rightarrow \infty}\left\|s_{n+1, l}-w_{n, l}\right\|=0$ and $\lim _{n \rightarrow \infty} s_{n+1, l}=$ $p^{*}$. In view of the closeness of $T_{l}$, it yields that $p^{*} \in T p^{*}$, that is, $p^{*} \in F\left(T_{l}\right)$. By the arbitrariness of $l \geq 1$, we have

$$
p^{*} \in \mathcal{F}=\bigcap_{i=1}^{\infty} F\left(T_{i}\right)
$$

Next, we prove that $p^{*} \in \Omega$. Since $x_{n+1}=\Pi_{C_{n+1}} x_{0} \in C_{n}$, it follows from (3.1) and (3.17) that

$$
\phi\left(x_{n+1}, u_{n}\right) \leq \phi\left(x_{n+1}, x_{n}\right)+\xi_{n} \longrightarrow 0 \quad(n \longrightarrow \infty) .
$$

Since $x_{n} \rightarrow p^{*}$, by virtue of Lemma 2.1 we have

$$
\lim _{n \rightarrow \infty} u_{n}=p^{*} .
$$

This together with (3.19) shows that $\left\|u_{n}-y_{n}\right\| \rightarrow 0$ and $\lim _{n \rightarrow \infty}\left\|J u_{n}-J y_{n}\right\| \rightarrow 0$. By the assumption that $r_{n} \geq a$, for all $n \geq 0$, we have

$$
\lim _{n \rightarrow \infty} \frac{\left\|J u_{n}-J y_{n}\right\|}{r_{n}}=0
$$

Since $H\left(u_{n}, y\right)+\left(1 / r_{n}\right)\left\langle y-u_{n}, J u_{n}-J y_{n}\right\rangle \geq 0$, for all $y \in C$, by condition $\left(\mathrm{A}_{1}\right)$, we have

$$
\frac{1}{r_{n}}\left\langle y-u_{n}, J u_{n}-J y_{n}\right\rangle \geq-H\left(u_{n}, y\right) \geq H\left(y, u_{n}\right), \quad \forall y \in C
$$

By the assumption that $y \mapsto H(x, y)$ is convex and lower semicontinuous, letting $n \rightarrow \infty$ in (3.32), from (3.30) and (3.31), we have $H\left(y, p^{*}\right) \leq 0$, for all $y \in C$. 
For $t \in(0,1]$ and $y \in C$, letting $y_{t}=t y+(1-t) p^{*}$, there are $y_{t} \in C$ and $H\left(y_{t}, p^{*}\right) \leq 0$. By conditions $\left(\mathrm{A}_{1}\right)$ and $\left(\mathrm{A}_{4}\right)$, we have

$$
0=H\left(y_{t}, y_{t}\right) \leq t H\left(y_{t}, y\right)+(1-t) H\left(y_{t}, p^{*}\right) \leq t H\left(y_{t}, y\right)
$$

Dividing both sides of the above equation by $t$, we have $H\left(y_{t}, y\right) \leq 0$, for all $y \in C$. Letting $t \downarrow 0$, from condition $\left(\mathrm{A}_{3}\right)$, we have $H\left(p^{*}, y\right) \leq 0$, for all $y \in C$, that is, $p^{*} \in \Omega$, and $p^{*} \in G=$ $\mathcal{F} \cap \Omega$.

(vi) We prove that $x_{n} \rightarrow p^{*}=\Pi_{G} x_{0}$.

Let $q=\Pi_{G} x_{0}$. Since $q \in G \subset C_{n}$ and $x_{n}=\Pi_{C_{n}} x_{0}$, we have

$$
\phi\left(x_{n}, x_{0}\right) \leq \phi\left(q, x_{0}\right), \quad \forall n \geq 0 .
$$

This implies that

$$
\phi\left(p^{*}, x_{0}\right)=\lim _{n \rightarrow \infty} \phi\left(x_{n}, x_{0}\right) \leq \phi\left(q, x_{0}\right)
$$

In view of the definition of $\Pi_{G} x_{0}$, from (3.35) we have $p^{*}=q$. Therefore, $x_{n} \rightarrow p^{*}=\Pi_{G} x_{0}$.

This completes the proof of Theorem 3.1.

\section{Conclusions}

Recently the extended general variational inequalities have been introduced and studied in Noor $[24,25]$. We would like to point out that the results and the methods presented in this paper will be used to study this kind of extended general variational inequalities and its multivalued version.

\section{Acknowledgment}

The authors would like to express their thanks to the referees for their helpful suggestions and comments.

\section{References}

[1] L.-C. Ceng and J.-C. Yao, "A hybrid iterative scheme for mixed equilibrium problems and fixed point problems," Journal of Computational and Applied Mathematics, vol. 214, no. 1, pp. 186-201, 2008.

[2] F. E. Browder, "Existence and approximation of solutions of nonlinear variational inequalities," Proceedings of the National Academy of Sciences of the United States of America, vol. 56, pp. 1080-1086, 1966.

[3] I. Cioranescu, Geometry of Banach Spaces, Duality Mappings and Nonlinear Problems, vol. 62, Kluwer Academic Publishers, Dordrecht, The Netherlands, 1990.

[4] Y. I. Alber, "Metric and generalized projection operators in Banach spaces: properties and applications," in Theory and Applications of Nonlinear Operators of Accretive and Monotone Type, A. G. Kartosator, Ed., vol. 178, pp. 15-50, Marcel Dekker, New York, NY, USA, 1996.

[5] S.-y. Matsushita and W. Takahashi, "A strong convergence theorem for relatively nonexpansive mappings in a Banach space," Journal of Approximation Theory, vol. 134, no. 2, pp. 257-266, 2005.

[6] S. Plubtieng and K. Ungchittrakool, "Hybrid iterative methods for convex feasibility problems and fixed point problems of relatively nonexpansive mappings in Banach spaces," Fixed Point Theory and Applications, vol. 2008, Article ID 583082, 19 pages, 2008. 
[7] S.-S. Chang, J. K. Kim, and X. R. Wang, "Modified block iterative algorithm for solving convex feasibility problems in Banach spaces," Journal of Inequalities and Applications, vol. 2010, Article ID 869684, 14 pages, 2010.

[8] S.-S. Chang, H. W. Joseph Lee, C. K. Chan, and L. Yang, "Approximation theorems for total quasi- $\varphi$ asymptotically nonexpansive mappings with applications," Applied Mathematics and Computation, vol. 218, no. 6, pp. 2921-2931, 2011.

[9] S. Homaeipour and A. Razani, "Weak and strong convergence theorems for relatively nonexpansive multi-valued mappings in Banach spaces," Fixed Point Theorem and Applications, vol. 73, 2011.

[10] S.-S. Zhang, "Generalized mixed equilibrium problem in Banach spaces," Applied Mathematics and Mechanics, vol. 30, no. 9, pp. 1105-1112, 2009.

[11] J. F. Tang, "Strong convergence theorem for a generalized mixed equilibrium problem and a family of quasi- $\varphi$-asymptotically nonexpansive mappings," Acta Mathematicae Applicatae Sinica, vol. 33, no. 5, pp. 878-888, 2010.

[12] R. P. Agarwal, Y. J. Cho, and N. Petrot, "Systems of general nonlinear set-valued mixed variational inequalities problems in Hilbert spaces," Fixed Point Theory and Applications, vol. 31, 2011.

[13] Y. J. Cho and X. Qin, "Systems of generalized nonlinear variational inequalities and its projection methods," Nonlinear Analysis, vol. 69, no. 12, pp. 4443-4451, 2008.

[14] Y. J. Cho, X. Qin, and J. I. Kang, "Convergence theorems based on hybrid methods for generalized equilibrium problems and fixed point problems," Nonlinear Analysis, vol. 71, no. 9, pp. 4203-4214, 2009.

[15] Y. J. Cho, I. K. Argyros, and N. Petrot, "Approximation methods for common solutions of generalized equilibrium, systems of nonlinear variational inequalities and fixed point problems," Computers $\mathcal{E}$ Mathematics with Applications, vol. 60, no. 8, pp. 2292-2301, 2010.

[16] Y. J. Cho and N. Petrot, "On the system of nonlinear mixed implicit equilibrium problems in Hilbert spaces," Journal of Inequalities and Applications, vol. 2010, Article ID 437976, 12 pages, 2010.

[17] Y. J. Cho and N. Petrot, "Regularization and iterative method for general variational inequality problem in Hilbert spaces," Journal of Inequalities and Applications, vol. 21, 2011.

[18] H. He, S. Liu, and Y. J. Cho, "An explicit method for systems of equilibrium problems and fixed points of infinite family of nonexpansive mappings," Journal of Computational and Applied Mathematics, vol. 235, no. 14, pp. 4128-4139, 2011.

[19] X. Qin, S.-s. Chang, and Y. J. Cho, "Iterative methods for generalized equilibrium problems and fixed point problems with applications," Nonlinear Analysis, vol. 11, no. 4, pp. 2963-2972, 2010.

[20] Y. Yao, Y. J. Cho, and Y.-C. Liou, "Iterative algorithms for variational inclusions, mixed equilibrium and fixed point problems with application to optimization problems," Central European Journal of Mathematics, vol. 9, no. 3, pp. 640-656, 2011.

[21] Y. Yao, Y. J. Cho, and Y.-C. Liou, “Algorithms of common solutions for variational inclusions, mixed equilibrium problems and fixed point problems," European Journal of Operational Research, vol. 212, no. 2, pp. 242-250, 2011.

[22] M. A. Noor, "Some developments in general variational inequalities," Applied Mathematics and Computation, vol. 152, no. 1, pp. 199-277, 2004.

[23] M. A. Noor, “General variational inequalities,” Applied Mathematics Letters, vol. 1, no. 2, pp. 119-122, 1988.

[24] M. A. Noor, "Some aspects of extended general variational inequalities," Abstract and Applied Analysis. In press.

[25] M. A. Noor, “Extended general variational inequalities," Applied Mathematics Letters, vol. 22, no. 2, pp. 182-186, 2009.

[26] M. A. Noor, K. I. Noor, and E. Al-Said, "Iterative methods for solving nonconvex equilibrium variational inequalities," Applied Mathematics E Information Sciences, vol. 6, no. 1, pp. 65-69, 2012.

[27] E. Blum and W. Oettli, "From optimization and variational inequalities to equilibrium problems," The Mathematics Student, vol. 63, no. 1-4, pp. 123-145, 1994.

[28] W. Takahashi and K. Zembayashi, "Strong and weak convergence theorems for equilibrium problems and relatively nonexpansive mappings in Banach spaces," Nonlinear Analysis, vol. 70, no. 1, pp. 45-57, 2009. 


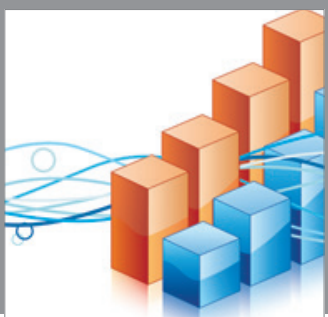

Advances in

Operations Research

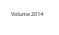

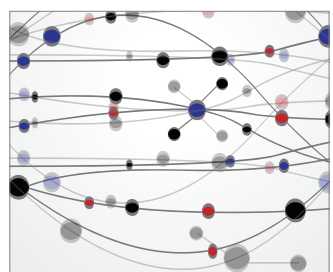

\section{The Scientific} World Journal
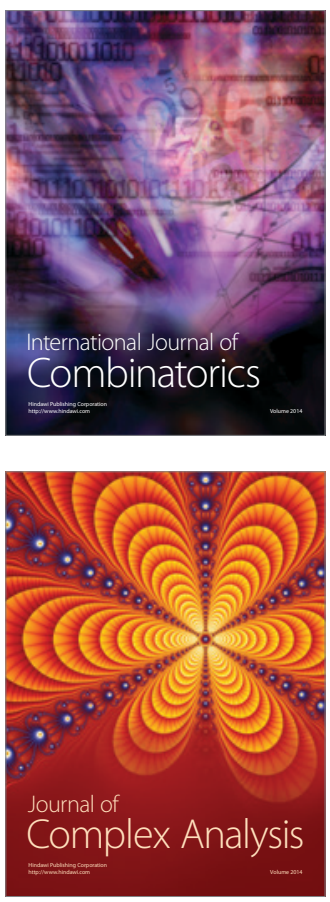

International Journal of

Mathematics and

Mathematical

Sciences
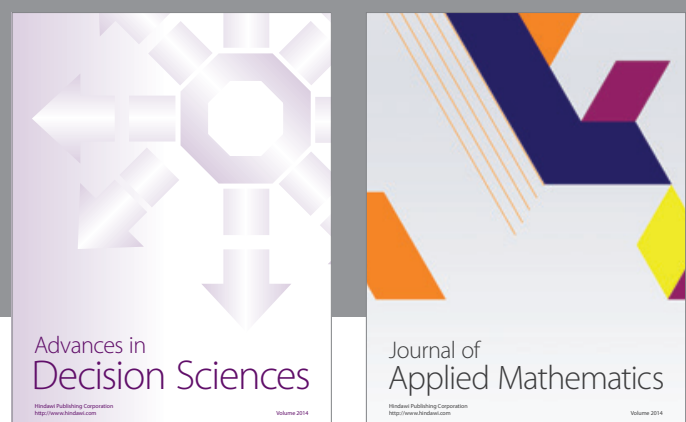

Journal of

Applied Mathematics
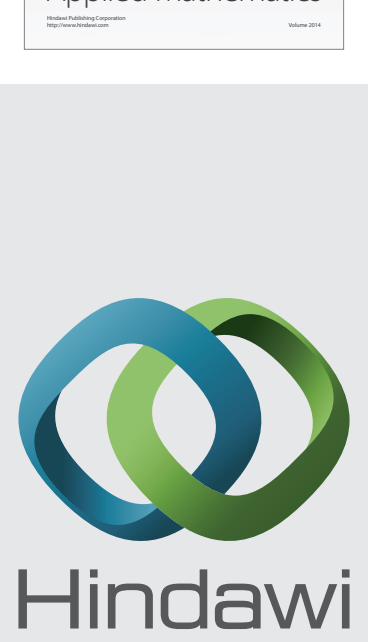

Submit your manuscripts at http://www.hindawi.com
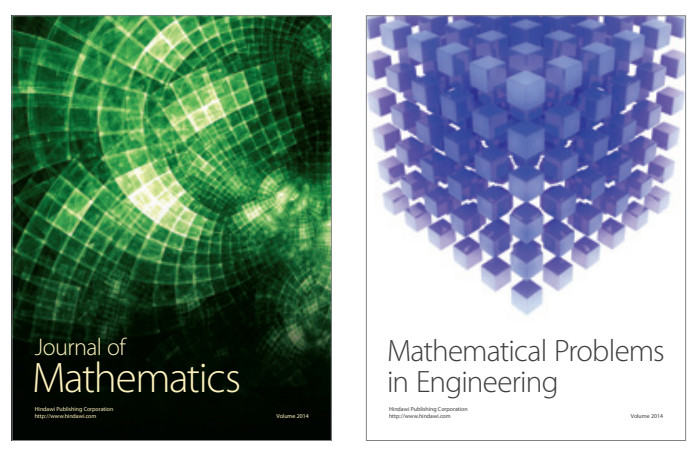

Mathematical Problems in Engineering
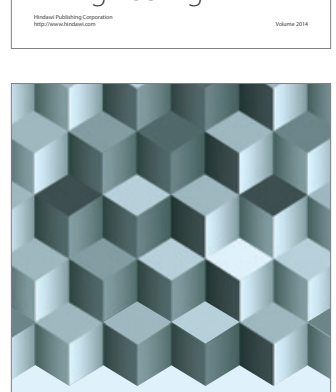

Journal of

Function Spaces
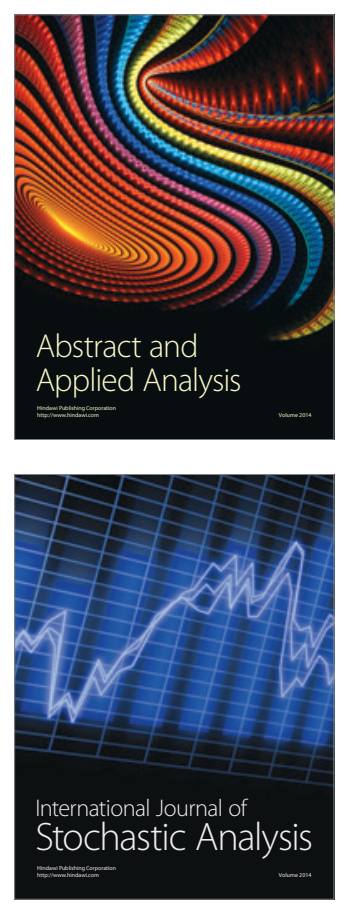

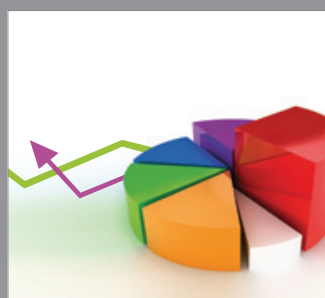

ournal of

Probability and Statistics

Promensencen
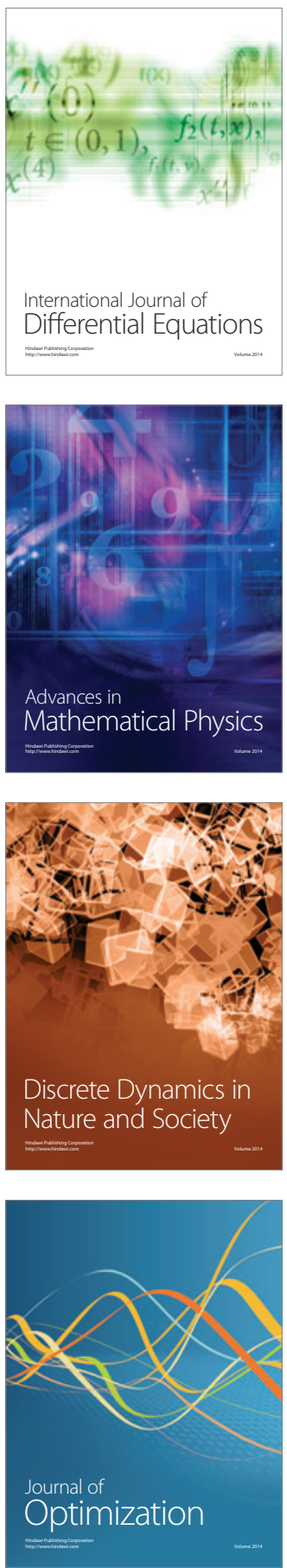